\title{
A study of abnormal semen parameters in infertile couples in Assam, India
}

\author{
Parija Juneja*, Pranay K. Phukan, Debojit Changmai
}

Department of Obstetrics and Gynecology, Assam Medical College and Hospital, Dibrugarh, Assam, India

Received: 30 December 2018

Accepted: 05 February 2019

\section{*Correspondence:}

Dr. Parija Juneja,

E-mail:pariijaa@gmail.com

Copyright: () the author(s), publisher and licensee Medip Academy. This is an open-access article distributed under the terms of the Creative Commons Attribution Non-Commercial License, which permits unrestricted non-commercial use, distribution, and reproduction in any medium, provided the original work is properly cited.

\begin{abstract}
Background: The importance of male factor contribution to infertility is well recognised. Semen analysis is an indispensable diagnostic tool in the evaluation of the male partners of infertile couples. Aim and objective of the study was conducted to determine the abnormalities in semen among male partners in infertile couples.

Methods: Detailed history, examination and semen analysis was done. Semen samples were analysed for volume, viscosity, sperm concentration, motility, and morphology, according to WHO guidelines.

Results: This study, done at a tertiary care center in north eastern India has demonstrated that abnormal semen quality is a major factor contributing to infertility in couples. Total number of participants were 94 . Most of the male partners i.e. $65.96 \%$, who came for infertility evaluation were between 30-39 years of age with $56.38 \%$ participants having abnormal semen parameters. The most common abnormality found was asthenozoospermia seen in $35.11 \%$ of cases followed by oligozoospermia seen in $25.53 \%$ of cases. Teratozoospermia and azoospermia were seen in $7.45 \%$ and $4.26 \%$ of cases respectively.

Conclusions: Males contribute towards infertility in couples significantly. Abnormal semen pattern is a common cause. More research is needed to render more valuable and significant results regarding male infertility.
\end{abstract}

Keywords: Male infertility, Semen abnormalities, Semen parameters

\section{INTRODUCTION}

The burden of infertility is often assumed to be the fault of the woman, as pregnancy and childbirth are manifested in her. Yet, "the male reproductive capacity was found to be deficient in not less than $50 \%$ of the infertile couples" (WHO manual for the standardized investigation and diagnosis of the infertile couple).

It is only within the last fifty years that the importance of the male factor contribution to infertility has been recognized. ${ }^{1}$ A male factor is solely responsible in about $20 \%$ of infertile couples and contributory in another 30$40 \% .^{2}$ Male reproductive and sexual function is also dependent on the intact function of the hypothalamic- pituitary-gonadal axis. The initiation and maintenance of normal quantitative and qualitative spermatogenesis requires adequate levels of both gonadotropins and testosterone.

Reduced male fertility may be the result of congenital and acquired urogenital abnormalities, infections of the genital tract, increased scrotal temperature as in varicocele, endocrine disturbances, genetic abnormalities and immunological factors.

In addition to numerical and structural defects of spermatozoa, functional male partner defects like erectile and ejaculatory dysfunctions have also increased tremendously in the recent years. 
Analysis of semen is the most important diagnostic tool for evaluation of male infertility. Semen parameters have been found to be important determinant of functional competence of the spermatozoa. . $^{3,4}$

It provides a wide range of information reflecting the spermatogenic and endocrine functions of the testes with functional state of secondary sex glands. Evaluation of semen parameters may suggest the possible causes of infertility and their identification could help to institute appropriate therapy.

The purpose of this study is to determine abnormal sperm parameters in male partners of infertile couples undergoing infertility evaluation and to provide an insight to the prevalence of low sperm count and abnormal semen parameters in North Eastern India and hence contribution of male factor to overall infertility.

\section{METHODS}

A prospective study carried out on infertile couples attending the outpatient department of Assam medical college and hospital, for a period of one year from 1st July 2016 to 30th June 2017.

A thorough history including medical, surgical and reproductive history was taken along with a proper physical examination.

The total number of participants were 94. Their semen analysis was done along with other required investigations. The inclusion and exclusion criteria were as follows.

\section{Inclusion criteria}

- All infertile couples coming for evaluation of infertility (both primary and secondary).

\section{Exclusion criteria}

- Those who did not give consent

- Those who find method of sample collection inconvenient

- Those who did not turn up for follow up

- Those who were on treatment for semen abnormalities

- Those who were on antibiotic prophylaxis.

\section{RESULTS}

Amongst total 94 participants, $53(56.38 \%)$ participants had abnormal semen parameters while 41 (43.62\%) had normal semen analysis as shown in (Figure 1). This shows that male factor infertility was present in $53.38 \%$ of infertile couples who came for evaluation of infertility. Maximum number of participants (65.96\%) were between 30-39 years.

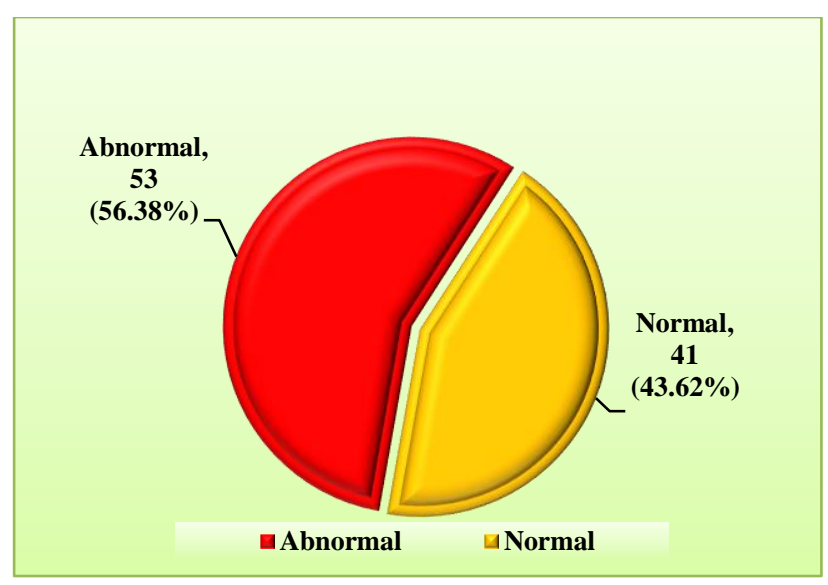

Figure 1: Semen quality.

The minimum age in the study population was 25 years and maximum age was 51 years. Twenty-one (22.34\%) participants were between 20-29 years of age, sixty-two $(65.96 \%)$ were between $30-39$ years and eleven $(11.7 \%)$ participants were equal to or more than 40 years of age as shown in (Figure 2).

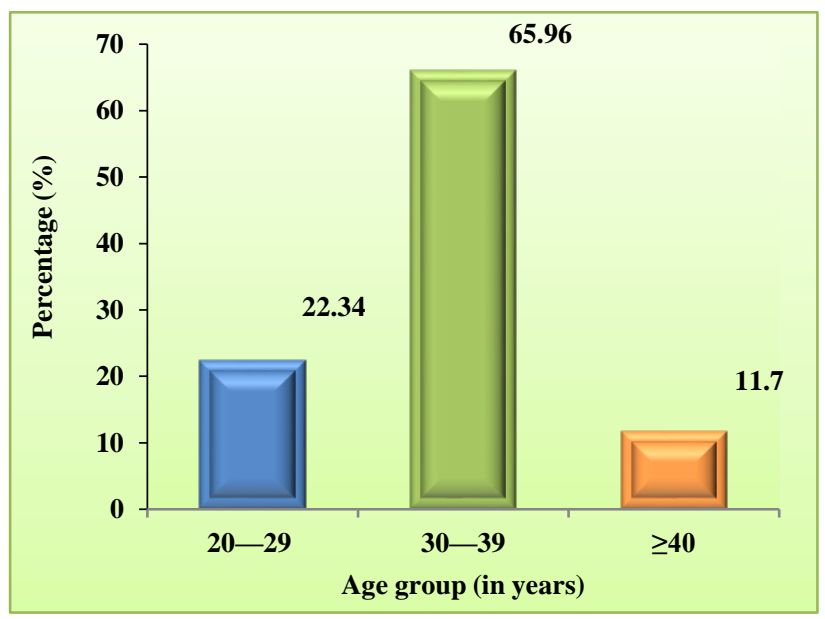

Figure 2: Age distribution.

The mean age of the participants was $34.10 \pm 5.98$ years.

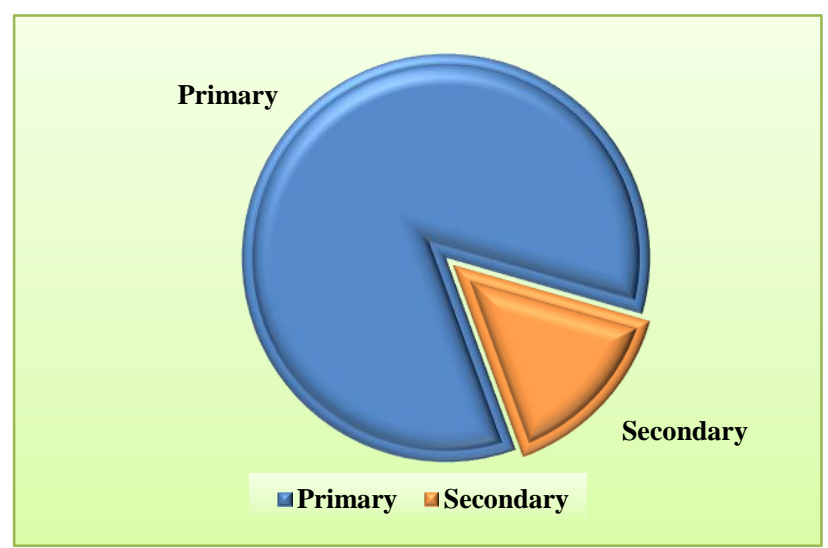

Figure 3: Type of infertility. 
Amongst 94 participants, 80 participants (84.1\%) presented as a case of primary infertility while 14 (14.9\%) were investigated for secondary infertility as shown in (Figure 3).

On physical examination of genitalia, abnormal curvature of phallus was seen in $2.13 \%$, undescended testes in $1.06 \%, \mathrm{~B} / \mathrm{L}$ small testes in $3.19 \%$, U/L small testes in $4.26 \%$, varicocele in $6.38 \%$ and hydrocele in $8.51 \%$ of the total cases as shown in (Table 1). The percentage distribution of various types of semen abnormalities observed in present study were: Asthenozoospermia was the most common abnormality detected.

Table 1: Physical findings noted in males presenting for infertility evaluation.

\begin{tabular}{|l|l|l|}
\hline Physical findings & Number $(\mathbf{n = 9 4})$ & Percentage \\
\hline $\begin{array}{l}\text { Abnormal curvature } \\
\text { of Phallus }\end{array}$ & 2 & 2.13 \\
\hline Undescended testes & 1 & 1.06 \\
\hline B/L small testes & 3 & 3.19 \\
\hline U/L small testes & 4 & 4.26 \\
\hline Varicocele & 6 & 6.38 \\
\hline Hydrocele & 8 & 8.51 \\
\hline
\end{tabular}

It was present in $35.11 \%$ of cases, oligozoospermia in $25.53 \%$, hypospermia in $13.82 \%$ and azoospermia in $4.26 \%$ of semen samples studied as shown in (Table 2).

Table 2: The abnormalities found in semen analysis of infertile men on evaluation.

\begin{tabular}{|l|l|l|}
\hline Type of abnormality & Number & Percentage \\
\hline Azoospermia & 4 & 4.26 \\
\hline Oligozoospermia & 24 & 25.53 \\
\hline Asthenozoospermia & 33 & 35.11 \\
\hline Teratozoospermia & 7 & 7.45 \\
\hline Hypospermia & 13 & 13.82 \\
\hline
\end{tabular}

Table 3 shows the distribution of mixed abnormalities i.e. the samples having multiple abnormal semen parameters. A total of 17 abnormal samples had mixed abnormalities. Asthenospermia/oligozoospermia was present in 10 $(58.9 \%)$, Astheno/teratozoospermia in $4(23.5 \%)$ and
Oligo/astheno/teratozoospermia in $(17.6 \%)$ cases out of total 17 cases of mixed abnormalities.

Table 3: Proportion of mixed sperm abnormalities in infertile men on evaluation.

\begin{tabular}{|l|l|l|}
\hline $\begin{array}{l}\text { Proportion of mixed } \\
\text { abnormalities }\end{array}$ & Number & $\%$ \\
\hline Astheno/oligozoospermia & 10 & 58.90 \\
\hline Oligo/teratozoospermia & 0 & 0.00 \\
\hline Astheno/teratozoospermia & 4 & 23.50 \\
\hline Oligo/astheno/teratozoospermia & 3 & 17.60 \\
\hline Total & 17 & 100.00 \\
\hline
\end{tabular}

\section{DISCUSSION}

There have not been many studies on male infertility in north eastern India. The present study gives an insight to the semen abnormalities in this part of India. Male factor infertility was present in $53.38 \%$ of infertile couples who came for evaluation of infertility in our hospital. Asthenozoospermia was found in $35 \%$ of cases and was the most common semen abnormality encountered in the present study. This is consistent with the study by Jajoo et al, done in Central India. ${ }^{5}$

A study by Khan et al, (2011 Pakistan) showed similar results. ${ }^{6}$ In a Nigerian study by Ugwuja et al, motility defects were more common. ${ }^{7}$ However, a study by Joshi et al, done in Bangalore and a study done by Pant PR in 2013 Nepal, showed oligozoospermia to be the commonest (Table 4). ${ }^{8,9}$

Table 4: Most common semen abnormality found in various studies.

\begin{tabular}{|c|c|}
\hline Study & $\begin{array}{l}\text { Most common semen } \\
\text { abnormality found }\end{array}$ \\
\hline Ugwuja et al, Nigeria $^{7}$ & Asthenozoospermia \\
\hline Khan et al, Pakistan ${ }^{6}$ & Asthenozoospermia \\
\hline Pant PR, Nepal ${ }^{9}$ & Oligozoospermia \\
\hline Joshi et al, Bangalore, India ${ }^{8}$ & Oligozoospermia \\
\hline Jajoo et al, Wardha, India ${ }^{5}$ & Asthenozoospermia \\
\hline Present study & Asthenozoospermia \\
\hline
\end{tabular}

Table 5: Semen analysis reports in various studies.

\begin{tabular}{|c|c|c|c|c|}
\hline Study & Azoospermia (\%) & Oligozoospermia (\%) & Asthenozoospermia (\%) & Teratozoospermia (\%) \\
\hline MS Khan et al, Pakistan ${ }^{6}$ & 10 & 23.2 & 35.2 & 2.4 \\
\hline Jarow JP et al, USA ${ }^{10}$ & 10 & - & - & - \\
\hline Aduloju et al, Nigeria ${ }^{11}$ & 3.4 & 34.8 & 26.9 & 6.5 \\
\hline $\begin{array}{l}\text { Bhattacharyya et al, } \\
\text { West Bengal }^{12}\end{array}$ & 12.42 & 19.87 & 4.35 & 4.35 \\
\hline Joshi et al, Bangalore $^{8}$ & 11 & 36 & 26 & 28 \\
\hline Present study & 4.26 & 25.53 & 35.1 & 7.45 \\
\hline
\end{tabular}


In the present study Azoospermia was found in $4.26 \%$, oligozoospermia in $25.53 \%$, teratozoospermia in $7.45 \%$ and hypospermia in $13.82 \%$ of the cases. The distribution of various abnormalities according to their occurrence can be compared with other studies as shown below (Table 5).

Most of the male partners were between 30-39 years of age. The duration of infertility was less than 5 yrs in $52 \%$, between 5-10 years in $46 \%$ and more than 10 years in $2 \%$ of infertile couples who came for infertility evaluation. Thus, it depicts that most of the couples came for evaluation within 5years of inability to conceive. Similar attendance was seen in study by Jajoo et al, Jain et al and Joshi et al. ${ }^{5,8,13}$ These regional differences might be due to ethnic, environmental, nutritional, socio economic or lifestyle factors. The identification and treatment of reversible conditions may be useful to improve male fertility.

\section{CONCLUSION}

Male factor abnormalities are significant contributors to infertility. Semen analysis remains to be the first test in evaluation of male infertility. The importance of regional differences in semen parameters due to environmental, lifestyle, socio economic, ethnic and genetic factors is well understood. The basis for prevention and treatment of male infertility would depend upon better knowledge on aetiology and accurate diagnosis of male reproductive system dysfunction.

Funding: No funding sources

Conflict of interest: None declared

Ethical approval: The study was approved by the Institutional Ethics Committee

\section{REFERENCES}

1. Isselbacher K, eds. Harrison's Principles of Internal medicine. 1994;13th ed:2006-2017.

2. Thonneau P, Marchand S, Tallec A, Ferial ML, Ducot B, Lansac J, et al. Incidence and main causes of infertility in a resident population (1 850 000) of three French regions (1988-1989). Human Reproduct. 1991;6(6):811-6.

3. Gyllenborg J, Skakebeak NE, Nielsen NC, Keiding N, Giwercman A. Secular and seasonal changes in semen quality among young Danish men: a statistical analysis of semen samples from 1927 donor candidates during 1977-1995. Int. J. Androl. 1999; 22 (1):28-36

4. Dohle GR. Inflammatory-associated obstructions of the male reproductive tract. Andrologia.2003;35(5): $321-4$

5. Jajoo S, Kalyani KR. Prevalence of abnormal semen analysis in patients of infertility at a rural setup in Central India. Int $\mathbf{J}$ Reproduct Contracept Obstetr Gynecol. 2013;2(2):161-4.

6. Khan MS, Deepa F, Ahmed Z, Tahir F, Khan MA. Assessment of male reproductive health by conventional method of semen analysis. J Ayub Md Coll A Abbottabad. 2011;23(1):84-8.

7. Ugwuja El, Ugwu NC, Ejikeme BN. Prevalence of low sperm count and abnormal semen parameters in male partners of women consulting at infertility clinic in Abakaliki, Nigeria. Afr Reprod Health. 2008;12(1):67-3.

8. Joshi P, Gopal N, Bhat V. Study of semen analysis patterns in infertile males. Internal J Pharm Biol Sci. 2011;1(1):44-9.

9. Pant PR. Abnormal Semen Parameters among Men in infertile couples. NJOG. 2013;8(1):53-5.

10. Jarow JP, Espeland MA, Lipshultz G. Evaluation of the azoospermic patients. J Urol. 1989;142(1):62-5.

11. Aduloju OP, Adegun PT. Factors predictive of abnormal semen parameters in male partners of couples attending the infertility clinic of a tertiary hospital in south-western Nigeria. Afr J Obstet Gynaecol. 2016;22(2):57-61

12. Bhaduri N, Sarkar AP, Dewasi N, Ghosh TK. Abnormalities in semen analysis among male partners of infertile couples: a study in a tertiary care level hospital of West Bengal, India.

13. Jain A, Puja Ambrish PI, Hoogar MB, Dhar R, Wani A, Agrwal S. Role of semen analysis in the diagnosis of infertility at a tertiary care centre in western India: a prospective study. Int J Reprod Contracept Obstet Gynecol. 2016;5(7):23.

Cite this article as: Juneja $\mathrm{P}$, Phukan $\mathrm{PK}$, Changmai D. A study of abnormal semen parameters in infertile couples in Assam, India. Int J Reprod Contracept Obstet Gynecol 2019;8:997-1000. 